\title{
Psychosocial functioning of young adults with cystic fibrosis and their families
}

\author{
Caroline Blair, Ann Cull, Christopher P Freeman
}

\begin{abstract}
Background - The psychosocial functioning of adolescents and young adults with cystic fibrosis still living in the parental home was investigated. With its proven genetic aetiology cystic fibrosis is an ideal model with which to assess the impact of a chronic and life threatening disorder on family and individual psychological and social functioning.

Methods - Twenty nine patients with cystic fibrosis and their families were compared with those of 27 patients with anorexia nervosa and 31 well controls. Assessments were made using self reporting, interview, and observational methods.

Results - Most patients with cystic fibrosis were in robust psychological health and only differed from their healthy peers in that they were much less likely to be in employment. Mothers of patients with cystic fibrosis or anorexia nervosa were more likely than the mothers of the well group to be emotionally distressed, although this was not so for fathers. Young people in both illness groups were more likely to have parents with high levels of expressed emotion. Most families of patients with cystic fibrosis had good problem solving abilities.

Conclusions - In spite of the burden of illness in cystic fibrosis psychological functioning in many respects matches that of well young people.
\end{abstract}

(Thorax 1994;49:798-802)

It is estimated that there are at least 2000 patients with cystic fibrosis over the age of 15 in the UK and that the prevalence is increasing at a rate of 100 cases a year. ${ }^{1}$ Survival needs to be matched by reasonable levels of psychosocial adjustment and quality of life. Epidemiological studies indicate a high prevalence of psychiatric disorder and distress in people with chronic physical illness. ${ }^{2}$ The early anecdotal accounts of young adults with cystic fibrosis ${ }^{34}$ painted a grim picture of high levels of distress in both patient and parents, although more recent reports have been more optimistic. ${ }^{5-11}$ Such research has suffered from certain limitations for example, an absence of control groups either of well subjects or of families coping with other illnesses, and overreliance on self reporting questionnaires without the counterbalance of clinical assessment. In addition, the way that families or patients describe themselves may differ from the way that clinicians see them and their views need to be determined.
This study aimed to compare the psychological health and family functioning of young adults with cystic fibrosis with that of well controls and patients with anorexia nervosa and their families. Anorexia nervosa was chosen for comparison because it is a serious illness with a mortality of $20 \%$ over a 20 year follow up. ${ }^{12}$ In common with anorexia nervosa, many patients with cystic fibrosis will be of low weight and have nutritional complications. Potentially important differences are that anorexia nervosa is thought to have a psychogenic aetiology and onset does not usually begin before adolescence.

\section{Methods}

SUBJECTS

Patients with cystic fibrosis were recruited consecutively from three regional cystic fibrosis centres serving the central belt of Scotland. Of the patients with anorexia nervosa $75 \%$ were recruited from the case register of a regional health authority with a specialist service for eating disorders. The remaining $25 \%$ came from a private clinic, again with a specialist service. They had all met the DSM-III-R ${ }^{13}$ diagnostic criteria for anorexia nervosa within the previous year. A well family was defined as one in which no member of the household had a chronic illness or had attended a specialist within the previous two years. The well controls were either nominated by the ill group families, which gave a good social class match, or - where geographical distance was a problem - were obtained from an alphabetical search of the lists of two general practices. Inclusion criteria were that the cystic fibrosis, anorexia nervosa, or well proband had to be aged between 14 and 24 years, still living in the parental home, and that parents or step-parents in the household agreed to be interviewed. Single parent households were not excluded.

A power analysis was used to determine sample size. Assuming a significance level of 0.05 and a power of $0.90,22$ subjects in each group would enable a difference between groups of about 10 points on the Family Assessment Measure (see below) to be detected. A total of 105 families were approached (35 in each group). There were $6 / 35,8 / 35$, and $4 / 35$ refusals from the cystic fibrosis, anorexia nervosa, and well families respectively. Reasons for refusal were established in all but three cases; family problems were sometimes the main reason for refusal and this applied equally to anorexia nervosa and cystic fibrosis families. Parents and the proband were equally likely to be the refuser.

Informed consent was obtained from both the proband and parent(s) and the project was approved by the local ethics committee. 
PROCEDURE

In the two illness groups an initial session was carried out in the clinic by an independent assessor blind to the aims of the study. She evaluated the psychosocial functioning and health status of the patient and collected demographic data. The second session was carried out by one of the authors (CB), usually in the family home. At this meeting the family assessments took place. For the well families all the assessments were carried out by $\mathrm{CB}$ in one meeting at the family home.

\section{MEASURES}

(1) A structured clinical interview able to identify DSM-III-R diagnoses for major depressive disorder was carried out with the proband.

(2) The General Health Questionnaire (GHQ30), ${ }^{14}$ a self reporting screening tool for emotional disturbance, was given to proband and parent(s).

(3) The Morgan and Russell Scales ${ }^{15}$ for anorexia nervosa. This is a guided interview during which detailed clinical information is obtained from both the patient and an informant (here the parents). It evaluates mental state, sexual and socioeconomic functioning, as well as eating behaviour.

(4) The Impact-on-Family scale, ${ }^{16}$ a selfreporting questionnaire which measures the financial, social and personal strains, and coping skills of families living with an ill child, was completed by both parents.

(5) The Family Assessment Measure (FAM), ${ }^{17}$ a self reporting questionnaire, was given to all members of the household aged 13 and over.

(6) The Camberwell Family Interview ${ }^{18}$ took place with the parent(s) alone. This was audiotaped and rated (by CB) for expressed emotion, ${ }^{18}$ a well established technique that seeks to take the "emotional temperature" of a household by evaluating a relative's negative effect or intrusive overconcern. A household is defined as having high expressed emotion if either parent makes a large number of "critical comments" about their child or shows high levels of "emotional overinvolvement". A high level of expressed emotion is a predictor of poor outcome and relapse in several psychiatric disorders. As a check against bias in the rater the tapes of 15 families ( 29 parents) were scored by an independent assessor. Inter-rater reliability was good. The number of critical comments made ranged from 0 to 10 and the mean difference between raters was 0.17 critical comments with the $95 \%$ limits of agreement ranging from -1.2 to +1.3 critical comments. As emotional overinvolvement is scored categorically the appropriate coefficient of agreement is weighted $\kappa$ and this was $0.84 .{ }^{19}$

(7) Problem solving task. The parents and the index child were asked to discuss together for up to 10 minutes each two problems salient to their household. These vignettes were audiotaped and rated for good, medium, or poor problem solving skills using a scoring manual developed in pilot work. A sample of 20 problem solving tapes was rated blind by an inde- pendent assessor and the weighted $\kappa$ score was 0.84 .

The health status of patients with cystic fibrosis was rated by their respiratory physician using the Cooperman scale. ${ }^{20}$ Lung function was measured by forced vital capacity (FVC) and forced expiratory volume in one second $\left(\mathrm{FEV}_{1}\right)$.

\section{Results}

Demographic features of the families are presented in table 1. While the anorexia nervosa and well families were well matched on social class, the cystic fibrosis families were more representative of Scotland as a whole. There were more boys in the cystic fibrosis group. Survival rates are better for boys with cystic fibrosis than girls, and girls were less likely than boys to be living with parents. Because of this bias all statistics were analysed for confounding effects of sex and class but none were found for the measures presented.

Health status of the probands is shown in table 2. Lung function of the patients with cystic fibrosis was comparable with that of a large British series. ${ }^{21}$ Eleven of the patients with cystic fibrosis had been treated with intravenous antibiotics during the three months before the interview. Five patients were on a transplantation waiting list. A third of the anorexia nervosa sample had made a partial recovery and no longer met the DSM-III-R weight criterion although the other core features of the illness remained. The patients with cystic fibrosis were typically in good psychological health. Only four of the group had had a previous encounter with a GP or hospital for mental health problems. Only one patient had received treatment at some time for a depressive illness compared with 12 in the anorexia nervosa group. None of the well probands had a mental health history. Using a cut-off score of $>5$ for "caseness" on the GHQ, five cystic fibrosis probands were "emotionally distressed" compared with six of the well group and 16 of the anorexia nervosa group $\left(\chi^{2}=12 \cdot 3\right.$; df 2 ; $\mathrm{p}<0.001)$. With increased age emotional distress in the cystic fibrosis proband was likely to be higher (although still low) (Spearman's $r=0.38 ; \mathrm{n}=29 ; \mathrm{p}<0.05)-$ an effect not found in the anorexia nervosa and well samples. As age could be confounded by the severity of illness a composite variable termed "cystic fibrosis severity" was derived by calculating the mean of weight, FVC, and $\mathrm{FEV}_{1}$, all three variables being expressed as a percentage of expected score for age and height. However, the relation of high emotional disturbance and severity of cystic fibrosis failed to reach statistical significance (Spearman's $r=-0.35 ; \mathrm{n}=29$; $\mathrm{p}>0.05)$. Patients with cystic fibrosis who had received intravenous antibiotics in the previous three months were compared with those who had not, again with no differences between groups. Of the sicker group 3/11 were emotionally distressed compared with $2 / 18$ in the fitter group $\left(\chi^{2}=0.37, p>0.05\right)$. In the group of patients on the transplantation list only $1 / 5$ fell into the distressed range. While personality was 
Table 1 Demographic characteristics of families

\begin{tabular}{|c|c|c|c|}
\hline & $\begin{array}{l}\text { Anorexia } \\
\text { nervosa } \\
(n=27)\end{array}$ & $\begin{array}{l}\text { Cystic } \\
\text { fibrosis } \\
(n=29)\end{array}$ & $\begin{array}{l}\text { Well } \\
(n=31)\end{array}$ \\
\hline $\begin{array}{l}\text { Mean (SD) age (years) } \\
\text { Male:female }\end{array}$ & $\begin{array}{l}18 \cdot 7(3 \cdot 2) \\
2: 25\end{array}$ & $\begin{array}{l}19 \cdot 2(2 \cdot 7) \\
20: 9\end{array}$ & $\begin{array}{l}18 \cdot 2(2 \cdot 6) \\
8: 23\end{array}$ \\
\hline $\begin{array}{l}\text { Work status } \\
\text { Student } \\
\text { Employed } \\
\text { Unemployed }\end{array}$ & $\begin{array}{l}66 \% \\
15 \% \\
19 \%\end{array}$ & $\begin{array}{l}35 \% \\
24 \% \\
41 \%\end{array}$ & $\begin{array}{r}67 \% \\
32 \% \\
0 \%\end{array}$ \\
\hline $\begin{array}{l}\text { Family structure } \\
\text { Two parent households } \\
\text { No. of children }\end{array}$ & $\begin{array}{l}85 \% \\
2 \cdot 4(1 \cdot 3)\end{array}$ & $\begin{array}{l}86 \% \\
2 \cdot 3(0 \cdot 7)\end{array}$ & $\begin{array}{l}94 \% \\
2 \cdot 2(0 \cdot 6)\end{array}$ \\
\hline $\begin{array}{l}\text { Social class }{ }^{1} \\
\text { I and II } \\
\text { III } \\
\text { IV and V }\end{array}$ & $\begin{array}{r}63 \% \\
37 \% \\
0 \%\end{array}$ & $\begin{array}{l}38 \% \\
52 \% \\
13 \%\end{array}$ & $\begin{array}{r}64 \% \\
29 \% \\
6 \%\end{array}$ \\
\hline
\end{tabular}

${ }^{1}$ Head of household: proportions expected for Scotland, 26\% 48\%, 25\% (General Register Office for Scotland, 1981).

Table 2 Health status of proband

\begin{tabular}{|c|c|c|c|c|}
\hline & $\begin{array}{l}\text { Anorexia } \\
\text { nervosa } \\
(n=27)\end{array}$ & $\begin{array}{l}\text { Cystic } \\
\text { fibrosis } \\
(n=29)\end{array}$ & $\begin{array}{l}\text { Well } \\
(n=31)\end{array}$ & \\
\hline $\begin{array}{l}\% \text { weight }^{1} \\
\text { Cooperman mean }(\mathrm{SD}) \\
\text { FVC mean (SD) } \\
\text { FEV }_{1} \text { mean (SD) }\end{array}$ & $\begin{array}{l}78 \cdot 7(15 \cdot 1) \\
- \\
-\end{array}$ & $\begin{array}{c}84 \cdot 5(12 \cdot 0) \\
5 \cdot 3(2 \cdot 8) \\
70 \cdot 8(6 \cdot 0) \\
58 \cdot 6(6 \cdot 0)\end{array}$ & $\begin{array}{l}94 \cdot 7(9 \cdot 2) \\
- \\
-\end{array}$ & \\
\hline $\begin{array}{l}\text { Morgan and Russell median } \\
\text { scores } \\
\text { Food intake } \\
\text { Menstrual } \\
\text { Socioeconomic } \\
\text { Psychosexual } \\
\text { Mental state } \\
\text { Average outcome }\end{array}$ & $\begin{array}{l}4 \\
0 \\
8 \\
7 \cdot 5 \\
8 \\
6 \cdot 4\end{array}$ & $\begin{array}{l}10 \\
12 \\
10 \\
10 \\
12 \\
10 \cdot 4\end{array}$ & $\begin{array}{l}12 \\
12 \\
12 \\
10 \\
12 \\
11\end{array}$ & $\begin{array}{l}\mathrm{H}^{2} \\
31 \cdot 4 \\
28 \cdot 2 \\
23 \cdot 8 \\
15 \cdot 2 \\
41 \cdot 3 \\
43 \cdot 9\end{array}$ \\
\hline
\end{tabular}

$\mathrm{FVC}=$ forced vital capacity; $\mathrm{FEV}_{1}=$ forced expiratory volume in one second.

${ }^{1}$ Percentage of expected for weight and height.
${ }^{2}$ Kruskal-Wallis ANOVA by ranks. All p values $<0.001$.

not formally measured, the clinical impression was that the young people with cystic fibrosis were indistinguishable from the well sample and quite distinct from the more troubled subjects with anorexia nervosa.

Each subscale on the Morgan and Russell has a maximum score of 12 denoting good functioning and a minimum score of 0 denoting poor functioning. Main effects for all the subscales were significant (table 2). The patients with cystic fibrosis had test profiles closer to the well group than the anorexia nervosa group. While this was only to be expected on the food intake and menstrual subscales, it is of note that both the mental state and psychosexual functioning scores for patients with cystic fibrosis matched the well controls. The socioeconomic subscale measures social relationships, social activities, educational, and economic performance. Here patients with cystic fibrosis functioned less satisfactorily than the well group, but in every case this was due to economic incapacity rather than social difficulty. Of the patients with cystic fibrosis 12 were unemployed compared with five of the anorexia nervosa and none of the well group (table 1).

On the GHQ $10 / 29$ cystic fibrosis mothers reached the criterion for caseness compared with $13 / 27$ anorexia nervosa mothers and 5/30 well mothers $\left(\chi^{2}=6.5 ; p<0.05\right)$. Numbers for fathers were $5 / 25,7 / 23$, and $7 / 26$ respectively $\left(\chi^{2}=1.4 ; \mathrm{p}>0.05\right)$.
The results of the Impact-on-Family scale are presented in table 3. Parents of patients with anorexia nervosa or cystic fibrosis experienced equivalent personal and social strain. Mothers of patients with cystic fibrosis felt under more financial strain than anorexia nervosa associated mothers, but this could be accounted for by the social class difference between groups. Both mothers and fathers of patients with cystic fibrosis had higher mastery scores, indicating that they felt more able to cope with the illness than parents of anorexia nervosa patients.

No differences between groups emerged when families were asked to describe themselves on the Family Assessment Measure $(F=0.95 ; \mathrm{df} 2,84 ; \mathrm{p}>0.05)$ and all scores were close to the population norms for this questionnaire. However patients with cystic fibrosis (10) and anorexia nervosa (11) were more likely to be living in high expressed emotion households as measured from the Camberwell Family Interview than the well families (1) $\left(\chi^{2}=13 \cdot 7\right.$; $\mathrm{p}<0.001)$. This was due to overinvolved rather than critical behaviour. Typical examples of overinvolved behaviour would be a mother who had given up all interests outside the home to be available for her daughter even though the child was well enough to cope with a full time job or a mother who persisted in infantalising her teenage son. Fourteen families of cystic fibrosis patients were categorised as good problem solvers compared with nine well families and three anorexia nervosa families $\left(\chi^{2}=8.07\right.$; $\mathrm{p}<0.02$ ).

\section{Discussion}

While it had been anticipated that patients with cystic fibrosis would be less emotionally disturbed than patients with anorexia nervosa, the most striking finding in the cystic fibrosis associated families was the robust psychological health of the patients who were indistinguishable from their healthy peers. This confirmed previous reports that depended on self reporting methods alone..$^{5-711}$ It signifies a change from the dismal picture of psychological functioning in patients with cystic fibrosis in the early uncontrolled studies. ${ }^{34}$ Even in the most severely affected group of patients - those awaiting heart-lung transplantation - levels of psychopathology were low. Of interest was the age appropriate social functioning of these young people many of whom, in spite of the physical limitations imposed by the disease, the social awkwardness of the symptoms, and shackles of the treatment regime, managed to relate appropriately to their peer group and to have close relationships with members of the opposite sex. Other studies have suggested that, where puberty is delayed and stature short, psychosexual functioning is likely to be compromised for healthy subjects and patients with cystic fibrosis alike. ${ }^{22} 23$ Unemployment was a problem for the cystic fibrosis group. The proportion of patients with cystic fibrosis who were not either in paid employment or students was very similar to that found in a recent large British survey of adults with cystic fibrosis. ${ }^{24}$ Employment was particularly difficult for 
Table 3 Mean (SD) results of Impact-on-Family scale

\begin{tabular}{|c|c|c|c|c|}
\hline & $\begin{array}{l}\text { Anorexia } \\
\text { nervosa }\end{array}$ & $\begin{array}{l}\text { Cystic } \\
\text { fibrosis }\end{array}$ & $t$ & $p$ \\
\hline $\begin{array}{l}\text { Fathers } \\
\text { Financial } \\
\text { Social } \\
\text { Personal strain } \\
\text { Mastery }\end{array}$ & $\begin{array}{l}\mathrm{n}=22 \\
10 \cdot 0(3 \cdot 1) \\
15 \cdot 9(2 \cdot 7) \\
15 \cdot 2(2 \cdot 7) \\
8 \cdot 7(1 \cdot 3)\end{array}$ & $\begin{array}{l}\mathrm{n}=25 \\
11 \cdot 1(2 \cdot 1) \\
16 \cdot 8(2 \cdot 6) \\
15 \cdot 8(1 \cdot 8) \\
7 \cdot 6(1 \cdot 6)\end{array}$ & $\begin{array}{r}1.50 \\
1.30 \\
0.95 \\
-2.76\end{array}$ & $\begin{array}{l}0 \cdot 13 \\
0 \cdot 22 \\
0 \cdot 36 \\
0 \cdot 008\end{array}$ \\
\hline $\begin{array}{l}\text { Mothers } \\
\text { Financial } \\
\text { Social } \\
\text { Personal strain } \\
\text { Mastery }\end{array}$ & $\begin{array}{l}\mathrm{n}=26 \\
9 \cdot 8(2 \cdot 4) \\
16 \cdot 3(2 \cdot 9) \\
16 \cdot 3(2 \cdot 0) \\
8 \cdot 8(1.9)\end{array}$ & $\begin{array}{l}\mathrm{n}=29 \\
11.5(3.2) \\
17.5(3.9) \\
17.3(2 \cdot 2) \\
7.7(1.8)\end{array}$ & $\begin{array}{r}2 \cdot 16 \\
1 \cdot 20 \\
1 \cdot 70 \\
-2 \cdot 30\end{array}$ & $\begin{array}{l}0 \cdot 04 \\
0 \cdot 22 \\
0 \cdot 09 \\
0 \cdot 03\end{array}$ \\
\hline
\end{tabular}

patients with cystic fibrosis from working class backgrounds, many of whom could have coped with flexible part-time employment had it been available.

It is well established that mothers of young children with cystic fibrosis suffer raised levels of emotional distress, ${ }^{2526}$ which is the case in many chronic illnesses. ${ }^{27} \mathrm{We}$ found that mothers of both cystic fibrosis and anorexia nervosa patients had raised levels of emotional distress compared with the well group. This confirms the finding of two uncontrolled studies $^{48}$ in patients with cystic fibrosis in the older age group. It should be noted, however, that the proportion of mothers with a mental health history $(18 \%)$ was the same in each group, and that mothers of the well group appeared to be "superwell" compared with a large community survey using the GHQ. ${ }^{28}$ Support for a minority of mothers may need to be continued well after the patient has reached the age of majority. The finding that the mental health status of fathers is indistinguishable from the well group has also been found in younger populations of patients with cystic fibrosis. ${ }^{825} 29$

Parents of both the anorexia nervosa and cystic fibrosis groups were more likely to be overinvolved with their child than parents of the well group, and this was more likely where illness was severe. However, the families of patients with cystic fibrosis as a whole functioned at a healthy adaptive level. They showed low levels of criticism, good problem solving skills, with clear communication, an ability to compromise, and were not afraid to tackle difficult issues. These family profiles had more in common with the well families than with the anorexia nervosa families.

Are there alternative explanations for these optimistic findings? It seems unlikely that sampling bias led to an exceptionally healthy group of cystic fibrosis patients being included in the study. More severely affected patients stood a greater chance of recruitment to the project because they attended the clinics more often. Young people living away from home and therefore excluded from the project tend to be a healthier group. ${ }^{30}$ Only two of the seven patients who refused to enter the study were known by the clinic to have family problems. Moreover, the well families were if anything "superwell" by virtue of being nominated as healthy by the "illness" families or by being chosen from GP lists. Of families on GP lists $30 \%$ did not meet the good health criterion for entry to the project.
No systematic positive bias could be detected in the reporting of their difficulties by the families. Where problems did exist patients and families appeared open and willing to describe their distress.

In all three groups a greater proportion of families were classified as middle class than in the population of Scotland as a whole. Overrepresentation of the middle classes in anorexia nervosa treatment centres is well known and explains the absence of patients in classes IV and $V$, and the $25 \%$ drawn from a private clinic. The middle classes are also over-represented in regional cystic fibrosis centres for adolescents and adults, ${ }^{21}$ and social class has a strong independent effect on age at death. ${ }^{31}$ Our samples were therefore representative of clinic populations. There were two reasons for the high proportion of middle class families in the well group. Families tended to nominate acquaintances who were either in the same or in a higher social class. On GP lists working class families were more likely to have a sick family member and were thus excluded from the sample. The main point of social class interest in the study was that, in spite of there being nearly twice as many working class families in the cystic fibrosis group as in the well group, the patients with cystic fibrosis and their families were functioning just as satisfactorily as their well peers. Levels of psychiatric disturbance are greater in lower social groups, ${ }^{32}$ so this finding was not anticipated.

Now that genetic screening for cystic fibrosis can identify over $85 \%$ of carrier couples, there is an implicit assumption that termination of an affected pregnancy or a decision to remain childless is preferable to having a child with cystic fibrosis. ${ }^{33}$ In the absence of mental retardation there is generally a reluctance to termination $^{34}$ and postal surveys suggest that over half the parents of children with cystic fibrosis would not terminate an affected pregnancy. ${ }^{35} 36$ The views of adults with cystic fibrosis and their parents are unknown, but this study suggests that in many respects quality of life for patients with cystic fibrosis and their families can equal that of well families. Consequently, where screening programmes are introduced, counselling should emphasise both the positive and negative aspects of cystic fibrosis and its effect on family life so that couples can make a fully informed choice on their reproductive future.

This study was funded by the Leverhulme Trust. We thank Dr Paul Chiswick, Ms Maisie Gard, Dr Andrew Greening, Dr Marion Keston, Dr Richard Legge, Dr Danie le Grange, Dr Morris McRae, Dr Bryan Stack, Mrs Wilma Warwick, and Dr Robert Wrate for their help with the project.

1 Report of the Royal College of Physicians. Cystic fibrosis in adults. Recommendations for care of patients in the UK. London: Royal College of Physicians, 1990

2 Wells KB, Golding JM, Burnam MA. Psychiatric disorder in a sample of the general population with and without a sample of the general population with and without
chronic medical conditions. $A m \quad f$ Psychiatry chronic medical

3 Teicher JD. Psychological aspects of cystic fibrosis in children and adolescents. Calif Med 1969;110:371-4.

4 Boyle IR, Di Sant'Agnese PA, Sack S, Millican F, Kulczycki LL. Emotional adjustment of adolescents and young adults with cystic fibrosis. I Pediatr 1976;88:318-26.

5 Simmons RJ, Corey M, Cowen L, Keenan N, Robertson J, Levison $\mathrm{H}$. Emotional adjustment of early adolescents with cystic fibrosis. Psychosom Med 1985;47:111-22. 
6 Cowen L, Corey M, Simmons R, Keenan N, Robertson J Levison $\mathrm{H}$. Growing older with cystic fibrosis: psychologic adjustment of patients more than 16 years old. Psychosom Med 1984;46:363-76.

7 Cappelli M, McGrath PJ, Heick CE, MacDonald NE, Feldman W, Rowe P. Chronic disease and its impact. adolescent's perspective $\mathcal{f}$ Adolesc Health Care 1989;10:283-8.

8 Bywater EM. Adolescents with cystic fibrosis: psychosocial adjustment. Arch Dis Child 1981;56:538-43.

9 Moise JR, Drotar D, Doershuk CF, Stern RC. Correlates of psychosocial adjustment among young adults with cystic fibrosis. F Dev Behav Pediatr 1987;8:141-8.

10 Sinnema G, Bonarius HC, Van der Laag H, Stoop JW. The development of independence in adolescents with cystic fibrosis. 7 Adolesc Health Care 1988;9:61-6.

11 Shepherd SL, Hovell MF, Harwood IR, Granger LE, Hofstetter CR, Molgaard C, et al. A comparative study of the stetter CR, Molgaard C, et al. A comparative study of the psychosocial assets of adults with cystic

12 Ratnasuriya RH, Eisler I, Szmukler GI, Russell GF. Anorexia nervosa: outcome and prognostic factors after 20 years. Br f Psychiatry 1991;158:495-502.

13 American Psychiatric Association. Diagnostic and statistical manual of mental disorders. 3rd ed. 1987.

14 Goldberg D. The users' guide to the GHQ. NFER Publications, 1987.

15 Morgan HG, Hayward AF. Clinical assessment of anorexia nervosa. The Morgan-Russell outcome assessment schedule. Br f Psychiatry 1988;152:367-71.

16 Stein REK, Riessman CK. The development of an impacton family scale. Med Care 1980;18:465-72.

17 Skinner H, Steinhauser P, Santa-Barbara J. The Family Assessment Measure. Can 7 Com Men Health 1983;2:91105.

18 Leff J, Vaughn C. Expressed emotion in families. London: Guilford Press, 1985

19 Bland JM, Altman DG. Statistical methods for assessing agreement between two methods of clinical measurement. Lancet 1986; : $: 307-10$

20 Cooperman EM, Park M, McKee J, Assad JP. A simplified cystic fibrosis scoring system (a preliminary report). Can Med Assoc ₹ 1971;105:580-2.

21 Penketh AR, Wise A, Mearns MB. Cystic fibrosis in adolescents and adults. Thorax 1987;42:526-32.
22 Landon C, Rosenfeld RG. Short stature and pubertal delay in cystic fibrosis. Pediatrician 1987;14:253-60.

23 Sinnema G. The development of independence in chronically ill adolescents. Int f Adol Med Health 1986;2:1-14.

24 Walters S, Britton J, Hodson ME. Demographic and social characteristics of adults with cystic fibrosis in the United Kingdom. BMF 1993;306:549-52.

25 McCrae WM, Cull AM, Burton L, Dodge J. Cystic fibrosis: parents' response to the genetic basis of the disease. Lancet 1973;ii:141-3.

26 Gayton WF, Friedman SB, Tavormina JF, Tucker F. Children with cystic fibrosis: I. Psychological test findings of patients, siblings, and parents. Pediatrics 1977;59:888-94.

27 Cadman D, Rosenbaum P, Boyle M, Offord DR. Children with chronic illness: family and parent demographic characteristics and psychosocial adjustment. Pediatrics 1991;87:884-9.

28 Cox B, Blaxter M, Buckle A. The health and lifestyle survey. Cambridge Health Promotion Research Trust, 1987.

29 Nagy S, Ungerer JA. The adaptation of mothers and fathers to children with cystic fibrosis: a comparison. Children's Health Care 1990;19:147-54

30 Levine SB, Stern RC. Sexual function in cystic fibrosis. Relationship to overall health status and pulmonary disease severity in 30 married patients. Chest 1982;81:422-8.

31 Britton JR. Effects of social class, sex, and region of residence on age at death from cystic fibrosis. BMF 1989;298:483-7.

32 Holzer CE, Shea B, Swanson JW, Leaf PJ, Myers JK, George L, et al. The increased risk for specific psychiatric disorders among persons of low socio-economic status. Am f Psychiatry 1986;6:259-71.

33 Screening for cystic fibrosis (editorial). Lancet 1992;340:20910.

34 Faden RR, Chwalow AJ, Quaid K, Chase GA, Lopes C, Leonard $\mathrm{CO}$, et al. Prenatal screening and pregnant women's attitude toward the abortion of defective fetuses. Am f Public Health 1987;77:288-90.

35 Watson EK, Marchant J, Bush A, Williamson B. Attitudes towards prenatal diagnosis and carrier screening for cystic fibrosis among the parents of patients in a paediatric cystic fibrosis clinic. F Med Genet 1992:29:490-1.

36 Wertz DC, Janes SR, Rosenfield JM, Erbe RW. Attitudes toward the prenatal diagnosis of cystic fibrosis: factors in decision making among affected families. Am 7 Hum Genet 1992;50:1077-85 